\title{
Exploring Communal Technology Use in the Home
}

\author{
Uncovering Household Group-Efficacy
}

\author{
Martin J Kraemer \\ Dept. of Computer Science \\ University of Oxford \\ martin.kraemer@cs.ox.ac.uk
}

\author{
Ivan Flechais \\ Dept. of Computer Science \\ University of Oxford \\ ivan.flechais@cs.ox.ac.uk
}

\author{
Helena Webb \\ Dept. of Computer Science \\ University of Oxford \\ helena.webb@cs.ox.ac.uk
}

\begin{abstract}
Vacuum cleaners, dish washers, and computers have had a lasting impact on ordinary life, and the last wave of ubiquitous technology, smart home technology, once again alters social order and practices in the home. Increasingly pervasive and internet-connected, domestic technology has become a community concern. Communal use of technology poses complex challenges for research and practice, requiring new approaches. Our investigation (36 interviews) of perceptions and considerations of communal device use illustrates how ordinary life evolves facing known and newly evolving challenges. We report four main themes around living with and sharing technology by relating aspects of technology considerations to different social groups. Using these insights, we illustrate participant considerations of personal characteristics, and discuss self-efficacy as a way to look at technology considerations, social groups, and personal characteristics. We outline in three ways how the concept of group-efficacy can help shape further investigation.
\end{abstract}

\section{CCS CONCEPTS}

- Human-centered computing $\rightarrow$ Empirical studies in collaborative and social computing; Empirical studies in ubiquitous and mobile computing.

\section{KEYWORDS}

Communal Practices, Household Group-Efficacy, Smart Home

\section{INTRODUCTION}

As the current wave of technology for the homes evolves from "gadgets for enthusiasts" to dependable off-the-shelf solutions, technology once again disrupts ordinary, domestic life. Past generations of computing technology have had a lasting impact on household life and communal use, despite being intended to meet the needs of individuals [8]. The current wave of ubiquitous devices is increasingly pervasive and shared. While these devices proliferate in domestic environments, they are largely unfamiliar to their inhabitants. Families, flat shares, short and long term lets are all challenged with the intricacies of introducing, managing, and using internet-connected technology.

Permission to make digital or hard copies of all or part of this work for personal or classroom use is granted without fee provided that copies are not made or distributed for profit or commercial advantage and that copies bear this notice and the full citation on the first page. Copyrights for components of this work owned by others than the author(s) must be honored. Abstracting with credit is permitted. To copy otherwise, or republish, to post on servers or to redistribute to lists, requires prior specific permission and/or a fee. Request permissions from permissions@acm.org.

HTTF 2019, November 19-20, 2019, Nottingham, United Kingdom

(C) 2019 Copyright held by the owner/author(s). Publication rights licensed to ACM. ACM ISBN 978-1-4503-7203-9/19/11 ..\$15.00

https://doi.org/10.1145/3363384.3363389
A multitude of domestic roles and responsibilities exist in our homes, and devices will only ever align with some of them. Some devices, like thermostats or home security systems, are designed for administration by an individual while they provide functionality to all householders. Other devices were designed with a single user in mind but are indeed used by many [9]. Members of communal settings establish their own ways to share resources and responsibilities; 'taking care of internet-connected devices' is consequently not a responsibility assumed by each user equally $[5,9,11,16,23]$. Different household members do not share the same attitude, knowledge, and preferences, but they use and manage technology in their own ways. These differences influence the use (or non-use) of technology and can lead to tensions between householders $[9,11,14]$.

The use of ubiquitous technology in homes is inevitably communal, requiring an understanding of individual and communal practices to design adequately [2-6, 23]. Future smart homes should empower inhabitants communally "to take an active part in controlling their set up, evolution and destruction" [17]. We need to understand the intricate ways in which smart home technology can fit with communal everyday work practices [17, 22].

This paper presents an investigation of communal use of technology in the home. We interviewed 36 householders on their use of technology in ordinary life, their preferences and attitudes, and explored how their households shared and used devices. Four major themes evolved from our analysis: dealing with technology-old and new, sharing personal devices, using shared devices, and dealing with guests and visitors. We investigate these themes following considerations of technology (ownership, responsibility, interaction, benefits, disadvantages) and their effect on social groups (personal, communal, external) and find that participants considered attitudes, aptitudes, preferences, skills, and competencies of others when arranging for communal use. These findings resembled notions of self-efficacy, a concept that has been used successfully to unpack personal technology use. Inspired by this, we propose groupefficacy as a lens to understand communal use, and we illustrate its usefulness in three different ways.

In Section 2, we briefly review related work, and we introduce our research methodology in Section 3. We present our findings in Section 4 which we continue to discuss in Section 5. We conclude this paper with suggestions for future work in Section 6 .

\section{RELATED WORK}

Communal use of technology in our homes has been researched extensively. More than two decades of research on personal computers illustrate the influence of technology adoption on social structure and power relationships in the home $[5,8,16,21]$, and 
similar influences are reported in more recent research on ubiquitous and internet-connected technology in our homes, turning our homes into 'smart homes' [11, 12, 15, 22].

Researchers allude to distributions of roles and responsibilities with regards to setup, use, and maintenance of smart home devices leading to tensions between household members [9, 14, 20]. Mennicken and Huang [14] find unfamiliarity among users caused a feeling of powerlessness and difficulties in getting high quality advice. They suggest future research into strategies of technically able household members that help shape the experience of their cohabitants. Tabassum et al. [20] also report on concerns expressed by those not setting up devices in the home which lead to abandoning a particular device. Geeng and Roesner [9] explored these tensions from a smart home administrator's perspective. They revealed tensions arising between different users and a 'concentration of expertise, access and control' with those setting up and maintaining devices.

Prior work focuses on individual experiences, perceptions, and attitudes in relation to smart home technology use. Singh et al. [19] research individuals' perceptions and attitudes toward smart home technology. Their participants perceive benefits of comfort, safety, and improvement of life but also raise concerns of autonomy and privacy. Forlizzi and DiSalvo [7] find some behavioural changes are intended or anticipated by participants, whereas other changes appear unintentional and incidental. The introduction of new technology challenges and changes traditional gender roles [10]. Hargreaves et al. [11] show how inhabitants negotiate the use of devices and navigate conflicts, while routines keep changing and evolving.

We approach the smart home considering householders' experiences with technology in general, inclusive of those who already own smart home devices and those who do not. An analytic structure emerges from our thematic analysis which allows us to map technology considerations onto social groups. This helps us to unpack participants' considerations of personal characteristics including attitudes, aptitudes, preferences, skills, and competencies. We shed light on understanding social negotiations, roles, and responsibilities in context of individual and communal technology use.

\section{METHODOLOGY}

To understand how our participants lived and experienced communal technology use, we required a broad account of individual and household perspectives. We found semi-structured interviews appropriate to achieve this goal.

\subsection{Participants}

We applied thematic analysis to a series of interviews with 36 participants in the UK from November 2017 to March 2018 (Table 1). Participants were recruited from our department, through community centres and various online channels. As compensation, participants were offered a $£ 10$ voucher. Interviews were generally conducted in public spaces, and a few were conducted at participants' homes. The general public was invited to participate in interviews and, at first, we did not pre-screen participants. We started with focus on (a) general attitudes toward internet-connected technology in the home ( $\mathrm{n}=18)$, (b) followed by a focus on newer smart devices,

\begin{tabular}{llcrc}
\hline & & \multicolumn{3}{c}{ Skills } \\
\cline { 3 - 5 } Age & Gender & expert & competent & novice \\
\hline \multirow{2}{*}{$18-34$} & female & 0 & 7 & 2 \\
& male & 4 & 2 & 0 \\
\multirow{2}{*}{$5-64$} & female & 1 & 12 & 1 \\
& male & 5 & 2 & 0 \\
\hline
\end{tabular}

Table 1: Participants by age, gender, and self-reported technology competence

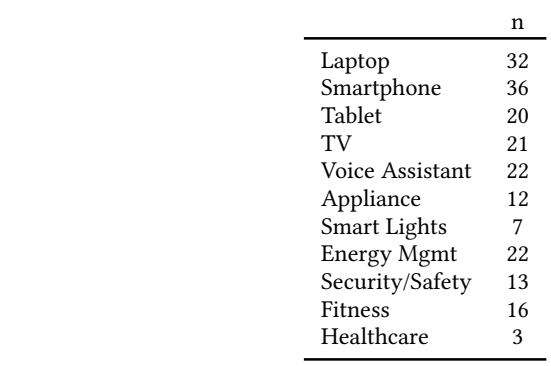

Table 2: Device ownership as reported by interviewees (n)

excluding entertainment and communication, $(\mathrm{n}=16)$ and $(\mathrm{c})$ social negotiation asking partners of previous participants to participate $(\mathrm{n}=2)$.

\subsection{Data Collection and Analysis}

Each interview lasted between 30 and 45 minutes. Participants were asked about the different devices they owned (Table 2), their general attitude, the purpose of or the intention to purchase a device, experiences of using the device as part of their daily routine, changes in their own behaviour or that of their cohabitants, and how they thought and felt about these changes. Participants were invited to comment on anything related to products they already owned and those they had learned about.

All interviews were transcribed verbatim by the main researcher. At the end of the first and second iteration, we hosted a coding verification session with other researchers in our department. The analysis started with initial and selective coding of a full, verbatim transcript and an in-case analysis of each individual interview, supported by the qualitative research software NViVo. Categories and themes evolved as codes and quotes were compared while further interviews were conducted.

\section{INTERVIEW FINDINGS}

In this paper, we report on the themes of Dealing with Technology, Sharing Personal Devices, Using Shared Devices, and Guests and Visitors from our thematic analysis. We report on these themes and supplement each theme by a diagram summarising relevant dimensions of technology consideration and social groups (see Technology considerations and social groups). 


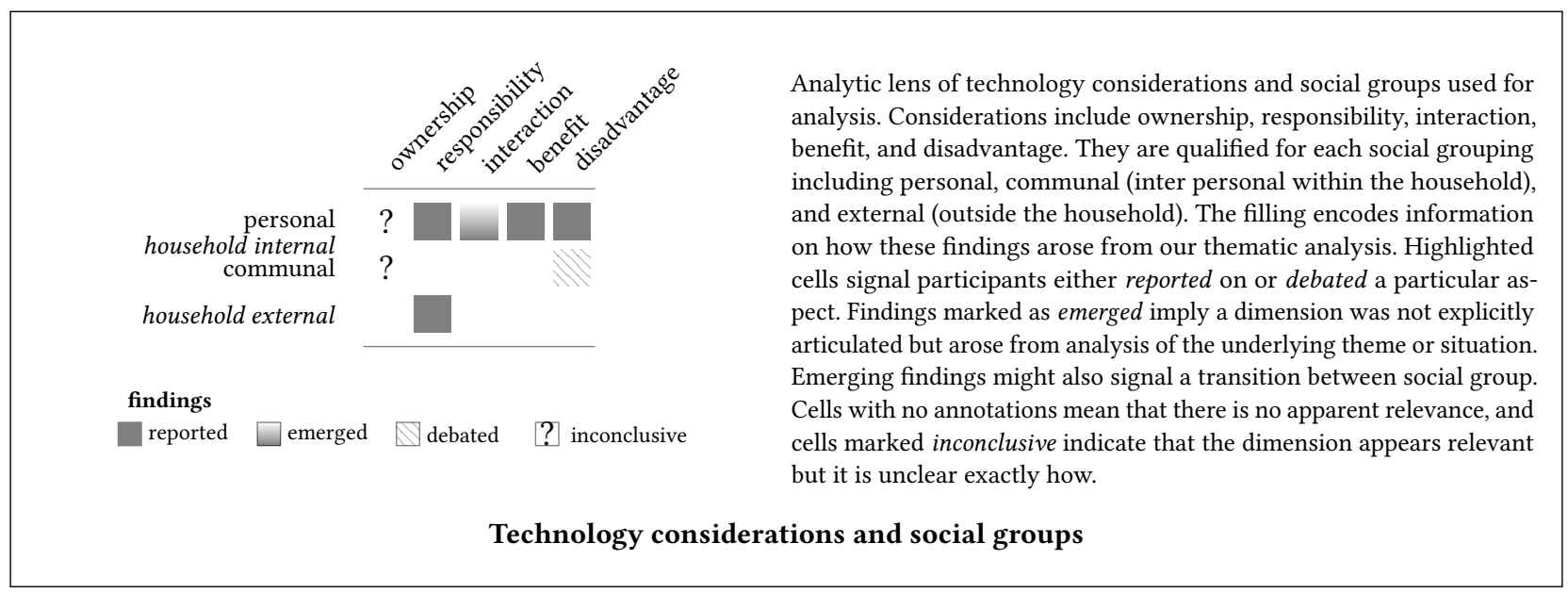

\subsection{Dealing with Technology-Old and New} When obtaining, using, and solving problems with technology, our participants reported largely relying on existing social and work relationships. Those providing advice expressed feelings of responsibility leading them to carefully consider their audience; and many of our participants to varying degrees provided advice to and sought help from others.

Support structures were based on participants' relationships and the expertise they saw both in themselves and in other people. Participants 032 and 034 observed how their parents were generally able to use handheld devices, while they relied on their children to find out about new features; they were "not very comfortable at all with fiddling around' (034). This difference in competence was also considered by participant 011 who found her mother incapable of using Microsoft Windows and hence opted for a Google Chromebook. 021 elaborated more broadly on his own expertise in providing technology support for family and friends. He found things like the internet or internet-connected kettles were too immature for many who lacked knowledge for setup and maintenance.

\begin{abstract}
Because if anything then it's one more thing that they cannot manage by themselves. So myself, I have regularly to get to my father to help him out. It's almost once every fortnight. [...] And he is still running office 2003. Even though it's not security updated and everything else. Because I can not help him with the newest version of Microsoft Office. (021, emphasis added)
\end{abstract}

A lack of support availability due to the novelty and immaturity of smart home devices were mentioned as particularly challenging.

With smart devices I probably wouldn't have anyone to go to. So I would look after them myself. [...] I would probably go to the local computer shop and ask somebody there. but they don't tend to know an awful lot more than I do. I think there's so much to know. (027, emphasis added)

We found the direction of technology advice in parentchild relationships could depend on expertise. While the adviser in the aforementioned cases was commonly younger than their receiving counterpart, we also learned about parents recommending the use of a particular smart home technology to their children. Two participants explained how they were motivated by their parents to install a home security system. It became apparent how benefits resulted on a personal (feeling safe), communal (looking after the dog), and close family (external) level (peace of mind); and how interacting with the system could be communal (looking after the dog) but was mainly personal.

Participant (015) talked about how catering for many different interests meant they were equipping their new house with many smart home devices. She had recently moved into a new house with her partner. As she was interested in "smart things" and her partner was "quite keen with security", they installed a smart home security system. This was complemented by fire safety devices as her father insisted on these. The father used a similar system and was also a retired fire fighter.

$$
\begin{aligned}
& \text { And I wanted to easily manage the utilities and hence the smart } \\
& \text { things. And my partner is quite keen with security. And then I } \\
& \text { guess we went kind of from the security system to the cameras } \\
& \text { for the dog. To the smoke alarm. Because my dad wanted it. } \\
& \text { (015) }
\end{aligned}
$$

The installation of new smart home technology could have unanticipated consequences for some household members. During the interview, the participant realised she now preferred doing online banking out of sight of the security cameras. The cameras covered the space in which she did online banking previously.

I used to work in the sitting room downstairs at the dining table. I now only go to the desk. Especially to do online banking but also shopping or anything that has sensitive information. (015)
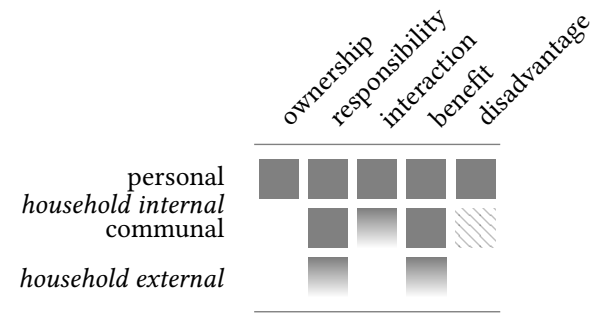

findings

reported $\square$ emerged $\$$ debated ? inconclusive

Summary of Theme 1

Feelings of responsibility by those external to a household emerged

from providing/seeking advice but could also provide "peace of mind"; interaction with personal devices could become communal; and household members could be disadvantaged by unanticipated consequences 


\subsection{Sharing Personal Devices}

Sharing personal devices could extend benefits of use to others; in other cases, sharing was infeasible due to usage patterns or cohabitants' aptitudes. Desktop computers, laptops, or mobile phones were largely considered as personal devices but could be shared under specific circumstances. Factors influencing the decision to share included the nature of the social relationship (e.g. parent child, spouses, close friends), the qualities of the device, and the perceived ability of the user. Several participants mentioned their partners accessing their laptops was permissible (e.g. 009, 017). Participant 032 explained how sharing access to laptops was fundamentally rooted in trust and intimacy. They had taken the decision to simply share everything, not distinguishing what was his and hers.

No not really. I mean we both have got logins to each others laptops. I mean.. I don't know if you are in a relationship or your friends are. But you know you sort of see couples that have been married for 50 years and still maintain separate bank accounts. (032)

However, being in an intimate relationship didn't mean access to devices would always be handled in the same way. Smart phones could be "too individual" (017) or used "so often" (029) that sharing was considered infeasible. Participant 006 mentioned she would not be interested in using her partner's device as its qualities did not appeal to her.

No actually. In fact I don't even know his computer password, and that's how we like it; and I don't like it as he has BlackBerry phone. I've got a nice phone. I don't need that. (006)

Asked to reflect on sharing personal devices, participants 012 and 028 pointed towards their partners aptitude in handling devices. They preferred to keep their devices separate and to handle any arising issues on their own. Participant 001 emphasised that sharing their laptops would "beg for divorce" (001) having previously emphasised the devices were "almost like a third family member" (001) that needed attention and care taking. However, participant 001 found exceptions to the rule existed, and participant 012 acknowledged her partners skillfulness in problem solving.

absolutely not.. actually that would beg for divorce. [...] actually you are making me think. sometimes if he is out, I'm using his computer to print and that's alright, that's okay. (001) but he is very good in finding out how things not work like Google and so... no, we keep our devices separate. (012)

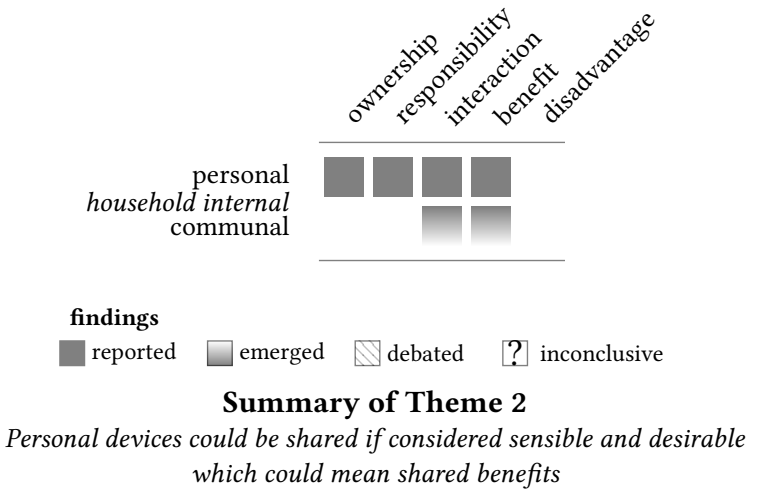

\subsection{Using Shared Devices}

4.3.1 Navigating communal use.

The use of shared (entertainment or recreation) devices was commonly negotiated by considering each others' needs and preferences, and sometimes simplified through redundancy of devices. Our participants commonly mentioned spending time with their partners or family watching television. They would agree on which programme to watch if there was no strong preference by any of them. If any one of them had a strong preference they would usually be given priority, but there was also the possibility to evade conflict by using a second device such as a tablet or a television in a different room.

I thought it was the most horrible vibe ever at first. Because $I$ don't want to watch what he's watching but I want to be in the same room as him. I tried reading books, but I can't read a book with the television on. (006, emphasis added)

Similarly, access to and use of the smart voice assistant owned by one flat mate was shared with a cohabitant. Participant 018 and her flatmate casually used their voice assistant while spending time together. The participant was also allowed to use the device without the owner (her flatmate) being present.

We use her [Alexa] for literally everything. Ask her what the
weather is like, ask her if we ever have a conversation and we
need to answer a question then we just ask her. (018) In other situations, shared access was technically not possible although socially permissible.

My friend's Spotify and Amazon Prime is connected to it, so when he is driving and listens to Spotify and then I come home and start using it, it will cut his music out (018)

Access to a cross trainer and smart lights was shared and negotiated based on personal preferences and interest, leading to a stronger claim of those driving procurement and adoption in the first place. When both householders wanted to use the cross trainer at the same time, the two householders would trade the use of the TV as a reward (035). The cross trainer of participant 028 supported different profiles for different users, avoiding conflicts over personalisation. Similarly, participant 009 would leave usage decisions for smart lights in the living room to her partner because he was 'a little bit annoying' (009).

(a) joint-use of the television personal
household internal
communal

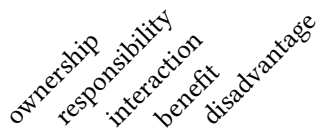

(b) using home trainer and smart lights

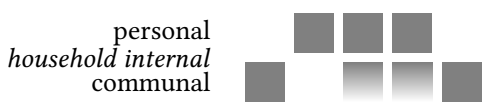

(c) joint-use of smart voice-assistant
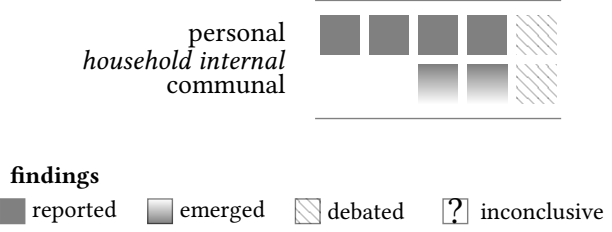

Summary of Sub-Theme 3.1

(a) Joint-use of mature technology, e.g. television, were common; (b) strong individual preferences could influence usage practices of newer devices, e.g. home trainer and lights, and communal benefits emerged while individuals could feel disadvantaged; (c) benefits emerged from sharing smart voice assistants and connected services (music streaming)

but participants debated disadvantageous technical limitations 


\subsubsection{Usage Practices.}

Our participants observed how they and their cohabitants developed different usage practices such as the use of different features of, different interfaces for, or different devices as interfaces to control a device; some relied on others to control devices.

When existing devices were replaced, not everyone used them to the same extent. Participant 019 observed how her daughter linked her phone to a smart speaker while she listened to internet radio only, and her husband did not want to use it, preferring his old stereo instead. Similarly, participant 016 recalled how his mother used a smart thermostat while his father preferred manual control over the heating, and participant 034's smart kettle was used as a "normal" kettle by his partner.

If he is feeling cold, he is going to walk up and press the button on the thing. I mean he has an iPhone, but I can't even get him to pick up FaceTime because he doesn't understand it. (016)

While participants in the aforementioned cases did not face any obvious drawbacks from their non-use of smart features, others reported disadvantages. For example, participant 026 reported how he used his smart phone to control the lights while his wife preferred their Google Home. However, it was not possible to control the smart plugs that way. A similar situation led participant 020 to an inconvenient work around to switch the lights on and off. While there were obvious solutions to both cases, the participants had not made use of them

No, she uses the Google Home. She tells the Google Home to turn the lights on. I haven't done an action for the smart plugs yet (026)

I then have to text or send a message to my boyfriend and go like. Can you turn the lights on? And that really frustrates me. (020)

Participant 020 had to use the lights as part of her daily routine and eventually installed the smart phone app to control them. She "made do" with the system as relying on her partner to act was infeasible. Participant 023 reported her mum chose to rely on her father to control the smart TV, only ever using it in his presence.

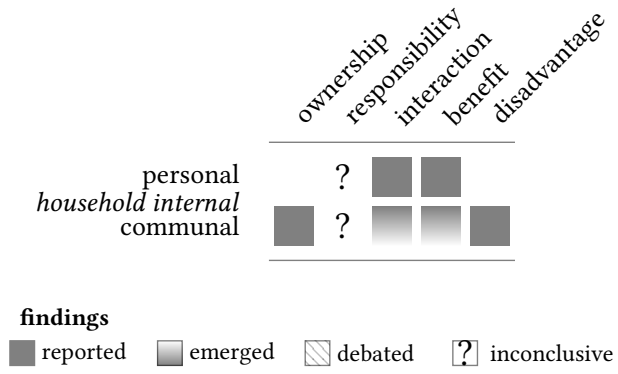

Summary of Sub-Theme 3.2

Different usage preferences, e.g. "unsmart" or manual use, meant benefits for the household were emerging, and these preferences could bring about disadvantages for the community

\subsubsection{Managing failure.}

Responsibilities to take care of the home network differed, but its use was commonly shared with some depending more on it than others.

Participant 001 split the work with her partner. While he was calling the provider, she would try switching the router off and on Similarly, participant 012 explained how her partner would attempt to fix the problem but she would call the provider if "it reached crisis”. Again slightly different was participant 021 's approach. To analyse any home network issue, his wife would give him a call and follow his guidance because the network setup was "a little more complicated".

Personal preference and expertise were also important factors for participants 010 and 020.020 argued her partner did not like being on the phone and the internet was not a priority for him. It would be her calling the provider and sorting out the issue. Whereas he was more likely to fix the television in a timely manner.

The use of a smart home setup as described by participant 015 provided benefits to all inhabitants, it also increased her reliance on technology. The participant explained how her phone broke and how she had to go 'back to being more manual' (015). While reassured that the system was still workable, it made her realise how useful the smart system was and also how much she had gotten used to it.

(a) managing a home network

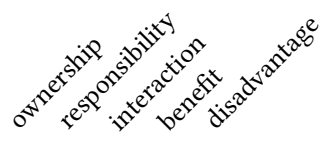
personal
household internal
communal

(b) spheres of expertise and breakdowns

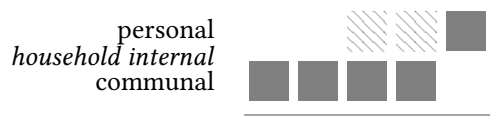

findings

$\square$ reported $\square$ emerged $\mathbb{N}$ debated $\quad[$ inconclusive

Summary of Sub-Theme 3.3

(a) The home network was shared responsibility with stakes distributed by expertise (emerging); (b) 'spheres of expertise' also extended to responsibility for personal devices and could disadvantage individuals in case of breakdowns

\subsubsection{Considering Cohabitants.}

When introducing internet-connected devices to the home, participants considered and involved their cohabitants to varying degrees. Responsibility, interaction, and benefit could be shared between householders if more experienced or interested individuals assumed responsibility of involving and educating others. For example, a smart home setup (e.g. lights and security cameras) was initially conceptualised and implemented by a single householder while influenced by all cohabitants.

Being aware. Participant 020 and 024 were a couple and both were interviewed separately. Participant 024 initially purchased smart sockets to control lights over the winter months, aiming to protect the house from burglaries. At the time of interviewing, the sockets had been re-purposed by 024 as part of a more permanent light system, turning it from burglar protection into a more permanent and shared system. The comments suggested that while both participants initially agreed on the purpose and use of the system, participant 020 had struggled with using them. Two months after installation, she was still adjusting to its requirements. The male householder (024) who had been driving the technology adoption, appeared to have some knowledge of that situation. 
I then have to text or send a message to my boyfriend and go like. Can you turn the lights on? And that really frustrates me.[...] I have got the app now. But it's so. It's a little bit annoying. Because if you are already upstairs, and then you want to put the light on or off [without having the phone]. (020)

She likes [pauses briefly], she doesn't mind but she is not overly involved. She is quite happy with the lights and turning them on and off and how easy that is. (024)

At the time of the interview, the couple had only been living together for half a year. The smart lights were the first "smart home system" they owned.

Ongoing consultation. Considerations could become more articulated with growing expertise. Participant (032) blogged about smart homes devices in his free time, bringing a high level of knowledge and expertise to the table. He highlighted how the use of new smart devices was subject to ongoing consultation. He semi-professionally reviewed new devices he had been sent by companies or purchased. It was his responsibility to configure, investigate and discuss the use of such devices with his partner (participant 036). The partner also trusted him to act responsibly in protecting the household from any risks related to these devices.

Part of it is the family acceptance factor. Can I get on with it. Can my wife get on with it. Can we get on with it when people come around. do they get one with it. And the other thing is how much effort it is. (032, emphasis added)

You don't really understand how this works either, do you. And he was like no I don't. So let's not do that that was a while ago and I can't really remember what it was. (036)

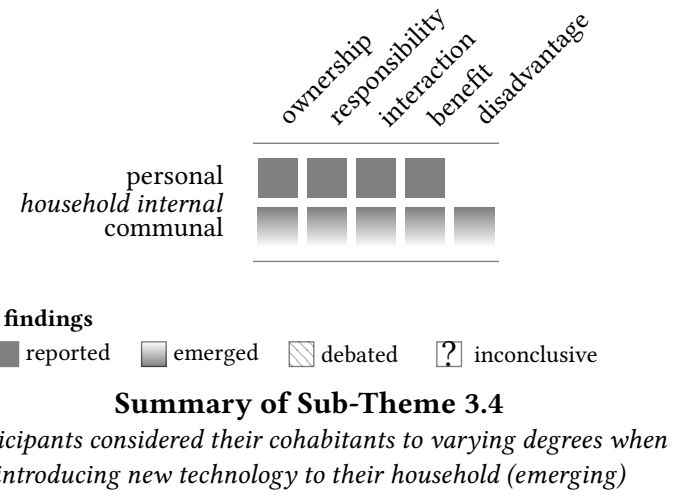

\subsection{Guests and visitors}

Considerations of other users, their unfamiliarity with the system and the need for access control, expanded beyond the household to include guests and other visitors (e.g. contractors). Unfamiliarity with a system could inconvenience visitors, particularly without efforts of introduction by hosts. In turn, the lack of access control could potentially disadvantage the household and its individuals. Participants' considerations ranged from hospitality for specific situations, e.g. accommodating parents $(020,036)$, to protecting systems from unwanted access (015). These considerations were driven by a range of factors including social norms of hospitality, intimacy, reliability, perceived ability, and personal preferences.

Issues of access. Two of our participants considered installing an Amazon Alexa in each bedroom. Participant 015 raised issues of access control, not wanting potential guests to have the same level of access to the device.

Dealing with unfamiliarity. Guests would not be expected to be familiar with the customs of and intricacies of "using" the home. Hence, participants found different ways to deal with their guests' unfamiliarity. For the duration of a short stay, the household of participant 020 deemed appropriate explaining but not providing means of control over smart lights to the participant's father. Furthermore, the father was perceived as not being capable or open to using new technology.

And he was like your light doesn't work. And we were like, no it does you just have to use the app. [...]

I think he just doesn't understand. My dad is not very good with technology. So, he was just like. What's the point in that. $(020$, emphasis added)

Because their parents/in laws stayed with them for four weeks, participants 032 and 036 considered reconfiguring their system. Participant 036 explained that after consideration of their guests' ability to control the smart home system using mobile phones, they reconfigured their smart home system to work independently of their mobile phones.

We actually had my parents living with us for four weeks [...] And that required quite a major reshuffle of everything that we had.[...] both of us work [...] [The system] just went into a sort of lock-down situation [when they left the house]. So a lot of stuff ended up getting disabled. (036)

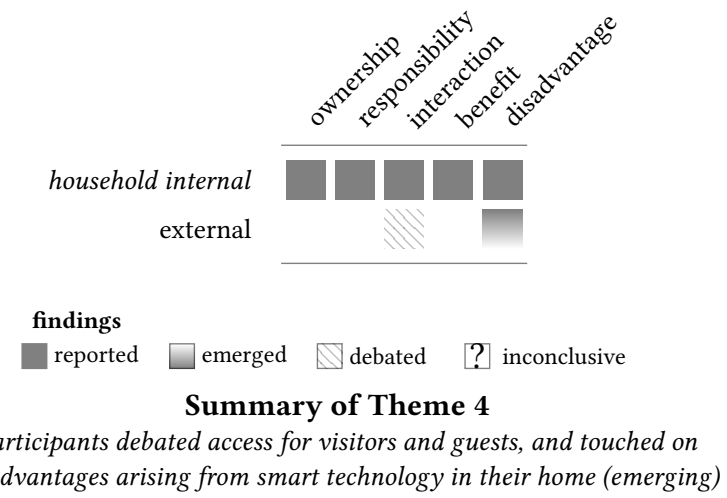

\section{DISCUSSION}

Users engage with technology within their situated contexts where features of their environments and their own sense making shape how they use and deal with technology. Differences in use and engagement occur between more mature internet-connected technologies and relatively 'new' smart devices, however, in all instances they are rooted in the communal context of the household. Technology design then needs to "[enable] people, themselves, to be smarter and proactive in their everyday working practices" [17]. Our findings emphasise the importance of considering the collective and the individual when doing so. We discuss our findings from a perspective of self-efficacy and illustrate how group-efficacy can help understand communal practices.

\subsection{Self-Efficacy}

As experienced users of internet-connected devices, many of our participants demonstrated high levels of self-efficacy in seeking or providing advice, using, and maintaining devices. Self-efficacy is defined as "people's beliefs about their capabilities to produce 
designated levels of performance that exercise influence over events that affect their lives" [1]. Self-efficacy is a driver for how individuals approach technical challenges - those with higher levels of self-efficacy see difficulty as a challenge to be overcome and adopt effective strategies for achieving their goals. Those with lower levels of self efficacy avoid such difficult tasks, are more easily discouraged and can even view these as threatening [1]. According to Bandura [1], self-efficacy is affected by four main factors: experience ("enactive attainment"), modelling/observing others succeed ("vicarious experience"), social persuasion (e.g. encouragement), physiological factors (e.g. perceptions of signs of distress).

Much of our participants confidence in being able to navigate issues with internet-connected devices, e.g. their smart phones, computers, home networks, and televisions, was based on their own expertise and that perceived in others. Considerations of attitude, aptitude, and preferences were projected onto others' when reflecting on their needs. With regards to smart home devices, our participants mentioned not having established support networks and an increased difficulty in navigating their communal use. They sought advice within their social networks, following established social relationships, and were guided by their own attitudes, preferences, and overall self-efficacy. Of particular interest was their consideration of not only their own, but other community members' abilities and aptitudes. These considerations, to varying extents, influenced their willingness to share and the nature of their advice. As our participants continued to make their own experiences, they shaped their cohabitants experience, provided advice to others and sought help from those they trusted. These practices somewhat aligned with the four main factors affecting self-efficacy; while those more apt to using smart home devices increased their selfefficacy by experience (enactive attainment), they also served as role models in their social groups (vicarious experience).

We believe that a key part of this communal behaviour can be termed group efficacy - which in the manner of Bandura's definition of self-efficacy we can define as a group's capability to produce designated levels of performance that exercise influence over the events that affect the lives of its members.

\subsection{Group Efficacy}

In the context of the home, group efficacy applies in a variety of different ways. The first revolves around the self-efficacy of each member of the group, and relates most to the use of communal devices. The second involves not the self-efficacy of every member, but the ability of the group to exercise influence over the technology that affects the lives of its members or has a communal impact. The third relates to the composition of the group, and considers that a household can have a relatively fluid group membership over time, which will affect its group efficacy. We explore each of these in turn below:

\subsubsection{Devices for communal use.}

When sharing personal devices, participants clearly considered the nature of social relationships, skills, traits, and expertise of others in their community. The decision to share smart phones, laptops, and the use of other gadgets was deeply rooted in these characteristics. Participants were less inclined to consider sharing when they described devices as too individual to be of convenient use for their partners. Also, their partners' skills and aptitude influenced how comfortable they felt with sharing.

"Using shared devices" was similarly influenced by personal relationships, skills, traits, and expertise. Moreover, cohabitants' skills, traits, and expertise also surfaced as important factors in decisions to buy, configure, and use such devices as they had an impact on the whole household. The most common communal device among many participants was the television. Redundancy (more than one device) and communal interaction (jointly watching a movie) implied a broad range of technology considerations across all social groupings.

In cases where devices are used by many members of the household, group efficacy can help to frame and explain different situations. In the case where every member of the group is capable of using the technology, the goals of the group that pertain to using the technology are met too. However, in cases where the technology is too novel, complex, or where individual members of the group have lower self-efficacy, we can see that others within the group play a role in ensuring that the group achieves its objectives or, indeed, express concerns that lead to devices being abandoned (c.f. awareness of option to delete video recordings [20] or power imbalances resulting from device use [9]). From our interviews we have seen several examples where individuals specifically configure devices to be used by others, use smart technology on behalf of others, and even allow for alternative control options to enable those that do not wish to use smart technology. Without a consideration of the wider group in which smart technology is being used and its group efficacy, it can be difficult to determine how appropriate or effective the technology will be.

\subsubsection{Devices with communal implications.}

In other cases, smart devices were not necessarily intended for collective use but they have a communal impact, e.g. smart security systems, thermostats, or even smart coffee machines $[13,18,20]$. Different users had different demands for personal characteristics, and participants reported how they and their cohabitants had different usage practices [9]. These included the use of different features and different interfaces for the same devices, the use of different devices as interfaces to control another device, and the preference to not use a device at all. Personal characteristics and technology considerations plaid a decisive role in managing failure of technology. However, varying personal characteristics among cohabitants required more elaborate considerations by individuals of smart home technology on behalf of the household.

Again, we believe that group efficacy is key factor here, but where the communal use of technology focuses on the abilities of community members, more important for devices that can impact the community is the setting of clear goals that capture the needs of every community member, and the need for an individual who has the capability to translate these into reality. In practice, our interviews showed that typically the instigator of the purchase of a smart device is instrumental in its configuration $[9,20]$. Our participants also took responsibility for ensuring the technology worked as intended and did not excessively impact members of the community. Exactly how the needs of the wider group were elicited and negotiated seemed highly variable and could be both implicit or explicit. 


\subsubsection{Household communities are fluid.}

Social groups in the home were not limited to a household but included guests, visitors, and neighbours [9]. Similar considerations of personal characteristics and qualities of social relationship (level of intimacy with parents, family, friends) became influential for technology considerations.

By varying the scope of which members are part of the group, the concept of group efficacy is applicable here too. Participants considered adjustments to their systems catering for different levels of technology aptitude and social intimacy for guests, visitors and even neighbours, and they navigated issues of access control and unfamiliarity with technology.

\section{LIMITATIONS AND FUTURE WORK}

Our paper builds on participants' self-reported behaviour and participants' observations of other household members ${ }^{1}$. These other household members might hold different perceptions of these practices. While this allowed us to also learn about participants' preferences, goals, and motivations, further observational research is needed. An enthnographic study of home technology use can help verify and expand our findings.

In future work, we aim to explore (1) group dynamics including roles and relationships to help understand levels of group efficacy; (2) how group efficacy can be useful and how it is related to selfefficacy; and (3) how group goals are elicited and enabled to help understand how motivation can be influenced.

Furthermore, research should explore the implications of group efficacy on the design and use of technology, both inside and outside the home. Building from Bandura [1] four main self-efficacy factors, we can explore how these factors can develop self and group efficacy in a home context. Interventions through design, research, and education are also promising approaches.

\section{CONCLUSION}

To enable users to be "smarter and proactive in their everyday working practices" [17], we need to better understand the social context in which they use technology, particularly the communal aspects of it. We reported findings from 36 interviews in which we asked our participants for their experience in using and managing devices. Along dimensions of technology considerations and social groups, thematic analysis provided four main themes for investigation: dealing with technology, sharing personal devices, using shared technology, and considering guests and visitors. Further analysis along these dimensions revealed participants' considerations of characteristics including attitude, aptitude, preferences, skills, and competencies.

Discussing practices and experiences in light of reported characteristics, we found self-efficacy provided a useful perspective in the analysis. We further argued for group-efficacy as a useful lens to explain communal use, and we illustrate three possible applications of group-efficacy: (1) acceptance of devices for communal use; (2) managing devices with communal implications; and (3) understanding fluid household communities. In our future work, we plan to further explore the relationship of self-efficacy, group-efficacy, and household use of technology.

\footnotetext{
${ }^{1}$ We interviewed two couples as separate individuals to get both their perspectives.
}

\section{ACKNOWLEDGMENTS}

This work was funded by a Research Institute in Science of Cyber Security (RISCS) small grant. The first author was supported by an EPSRC grant (EP/P00881X/1).

\section{REFERENCES}

[1] Albert Bandura. 1994. Self-Efficacy. In Encyclopedia of human behaviour, V. S. Ramachaudran (Ed.). Vol. 4. Academic Press, New York, 71-81. https://doi.org/ 10.4135/9781483386874.n481

[2] Andy Crabtree, Richard Mortier, Tom Rodden, and Peter Tolmie. 2012. Unremarkable Networking: The Home Network As a Part of Everyday Life. In Proceedings of the Designing Interactive Systems Conference (DIS '12). ACM, New York, NY, USA, 554-563. https://doi.org/10.1145/2317956.2318039

[3] Andy Crabtree, Tom Rodden, Peter Tolmie, Richard Mortier, Tom Lodge, Pat Brundell, and Nadia Pantidi. 2015. House rules: the collaborative nature of policy in domestic networks. Personal and Ubiquitous Computing 19, 1 (2015), 203-215.

[4] Andy Crabtree, Peter Tolmie, and Will Knight. 2017. Repacking 'Privacy' for a Networked World. Computer Supported Cooperative Work: CSCW: An International Journal 26, 4-6 (2017), 453-488.

[5] Paul Dourish and Ken Anderson. 2006. Collective Information Practice: Exploring Privacy and Security as Social and Cultural Phenomena. Human-Computer Interaction 21, 3 (2006), 319-342. https://doi.org/10.1207/s15327051hci2103 2

[6] Paul Dourish and Genevieve Bell. 2011. Divining a Digital Future: Mess and Mythology in Ubiquitous Computing. The MIT Press.

[7] Jodi Forlizzi and Carl DiSalvo. 2006. Service Robots in the Domestic Environment: A Study of the Roomba Vacuum in the Home. In Proceedings of the 1st ACM SIGCHI/SIGART Conference on Human-robot Interaction (HRI '06). ACM, New York, NY, USA, 258-265. https://doi.org/10.1145/1121241.1121286

[8] David Frohlich and Robert Kraut. 2003. The Social Context of Home Computing. Springer London, London, 127-162. https://doi.org/10.1007/1-85233-854-7_8

[9] Christine Geeng and Franziska Roesner. 2019. Who's In Control?: Interactions In Multi-User Smart Homes. In Proceedings of the 2019 CHI Conference on Human Factors in Computing Systems (CHI '19). ACM, New York, NY, USA, Article 268, 13 pages. https://doi.org/10.1145/3290605.3300498

[10] Tom Hargreaves, Michael Nye, and Jacquelin Burgess. 2010. Making energy visible: A qualitative field study of how householders interact with feedback from smart energy monitors. Energy Policy 38, 10 (2010), 6111-6119. https: //doi.org/10.1016/j.enpol.2010.05.068

[11] Tom Hargreaves, Charlie Wilson, and Richard Hauxwell-Baldwin. 2017. Learning to live in a smart home. Building Research \& Information 46, 1 (2017), 1-13. https://doi.org/10.1080/09613218.2017.1286882

[12] Rikke Hagensby Jensen, Yolande Strengers, Jesper Kjeldskov, Larissa Nicholls, and Mikael B. Skov. 2018. Designing the Desirable Smart Home: A Study of Household\&\#160;Experiences and Energy Consumption Impacts. In Proceedings of the 2018 CHI Conference on Human Factors in Computing Systems (CHI'18). ACM, New York, NY, USA, Article 4, 14 pages. https://doi.org/10.1145/3173574.3173578

[13] Josephine Lau, Benjamin Zimmerman, and Florian Schaub. 2018. Alexa, Are You Listening?: Privacy Perceptions, Concerns and Privacy-seeking Behaviors with Smart Speakers. Proc. ACM Hum.-Comput. Interact. 2, CSCW (nov 2018), 102:1--102:31.

[14] Sarah Mennicken and Elaine M. Huang. 2012. Hacking the Natural Habitat: An In-the-Wild Study of Smart Homes, Their Development, and the People Who Live in Them. In Pervasive Computing, Judy Kay, Paul Lukowicz, Hideyuki Tokuda, Patrick Olivier, and Antonio Krüger (Eds.). Springer, Berlin, Heidelberg, 143-160.

[15] Sarah Mennicken, Jo Vermeulen, and Elaine M. Huang. 2014. From Today's Augmented Houses to Tomorrow's Smart Homes: New Directions for Home Automation Research. In Proceedings of the 2014 ACM International foint Conference on Pervasive and Ubiquitous Computing (UbiComp '14). ACM, New York, NY, USA, 105-115. https://doi.org/10.1145/2632048.2636076

[16] Helen J. Richardson. 2009. A 'smart house' is not a home: The domestication of ICTs. Information Systems Frontiers 11, 5 (2009), 599-608.

[17] Yvonne Rogers. 2006. Moving on from Weiser's Vision of Calm Computing: Engaging Ubicomp Experiences. In Proceedings of the 8th International Conference on Ubiquitous Computing (UbiComp'06). Springer-Verlag, Berlin, Heidelberg, 404421. https://doi.org/10.1007/11853565_24

[18] Alex Sciuto, Arnita Saini, Jodi Forlizzi, and Jason I. Hong. 2018. "Hey Alexa, What's Up?": A Mixed-Methods Studies of In-Home Conversational Agent Usage. In Proceedings of the 2018 Designing Interactive Systems Conference (DIS '18). ACM, New York, NY, USA, 857-868. https://doi.org/10.1145/3196709.3196772

[19] Deepika Singh, Ismini Psychoula, Johannes Kropf, Sten Hanke, and Andreas Holzinger. 2018. Users' Perceptions and Attitudes Towards Smart Home Technologies. In Smart Homes and Health Telematics, Designing a Better Future: Urban Assisted Living, Mounir Mokhtari, Bessam Abdulrazak, and Hamdi Aloulou (Eds.). Springer International Publishing, Cham, 203-214. 
[20] Madiha Tabassum, Tomasz Kosinski, and Heather Richter Lipford. 2019. I don't own the data": End User Perceptions of Smart Home Device Data Practices and Risks. In Fifteenth Symposium on Usable Privacy and Security (SOUPS 2019). USENIX Association, Santa Clara, CA. https://www.usenix.org/conference/ soups2019/presentation/tabassum

[21] Alladi Venkatesh. 1996. Computers and Other Interactive Technologies for the Home. Commun. ACM 39, 12 (1996), 47-54. https://doi.org/10.1145/240483. 240491
[22] Charlie Wilson, Tom Hargreaves, and Richard Hauxwell-Baldwin. 2015. Smart homes and their users: a systematic analysis and key challenges. Personal and Ubiquitous Computing 19, 2 (2015), 463-476. https://doi.org/10.1007/s00779-0140813-0

[23] Eric Zeng, Shrirang Mare, and Franziska Roesner. 2017. End User Security \& Privacy Concerns with Smart Homes. In Proceedings of the Thirteenth USENIX Conference on Usable Privacy and Security (SOUPS'17). USENIX Association, Berkeley, CA, USA, 65-80. 